\title{
68 Ausdauersport und Immunität
}

\author{
(c) Springer-Verlag GmbH Deutschland, ein Teil von Springer Nature 2018 \\ D. Mathias, Fit und gesund von 1 bis Hundert \\ https://doi.org/10.1007/978-3-662-56307-6_68
}

Wichtige positive Effekte des Sports sind:

- Aktivierung von natürlichen Killerzellen, Granulozyten, Makrophagen und Akute-PhaseProteinen (= unspezifische Immunabwehr)

- Verbesserte Phagozytosefähigkeit der Immunzellen

- Entwicklung einer Toleranz gegenüber oxidativem Stress

Natürliche Killerzellen sind große Lymphozyten, die vor allem virusinfizierte Zellen, Tumorzellen, allerdings auch transplantiertes Fremdgewebe attackieren und vernichten. Die zytotoxische Kapazität beruht wie bei T-Lymphozyten auf Perforin und Granzyme. Bei Erkrankungen erfolgt ein Anstieg der Zellzahl innerhalb von 24 Stunden. Die Erhöhung hält 1-3 Tage an und nach 5-7 Tagen hat sich ihre Zahl wieder normalisiert.

Granulozyten sind am schnellsten einsatzbereit. Sie bauen Antigene direkt mit ihrem Peroxidasesystem ab. Bei bakteriellen Infektionen kann die Granulozytenzahl auf das 2- bis 6-Fache ansteigen.

Makrophagen als sog. Fresszellen koppeln mit ihren Toll-like Rezeptoren an Krankheitserreger, verdauen sie und stehen so als antigenpräsentierende Zellen den Lymphozyten zur Verfügung. Sie produzieren u.a. auch das entzündungs- und schmerzhemmende Interleukin 10, bei Sporttreibenden in höherer Konzentration als bei Nichtsportlern.
Akute-Phase-Proteine (APP) wirken als Mustererkennungsrezeptoren. Sie binden an Molekülstrukturen der Infektionserreger und machen sie so für die Granulozyten oder Makrophagen kenntlich. Das C-reaktive Protein ist ein solches APP. Es kann beim Sport belastungsabhängig bis zum Mehrfachen der Norm ansteigen, ist bei Sportlern in Ruhe aber eher erniedrigt (Fedewa et al. 2016).

Die Entwicklung einer Toleranz gegenüber oxidativem Stress ist möglich, weil die Aktivitäten speziell solcher Enzyme gesteigert werden, die reduzierend wirken. Bei Ausdauersportlern werden geringere Mengen an reaktiven Sauerstoffverbindungen gemessen als bei Nichtsportlern ( $\triangleright$ Kap. 27).

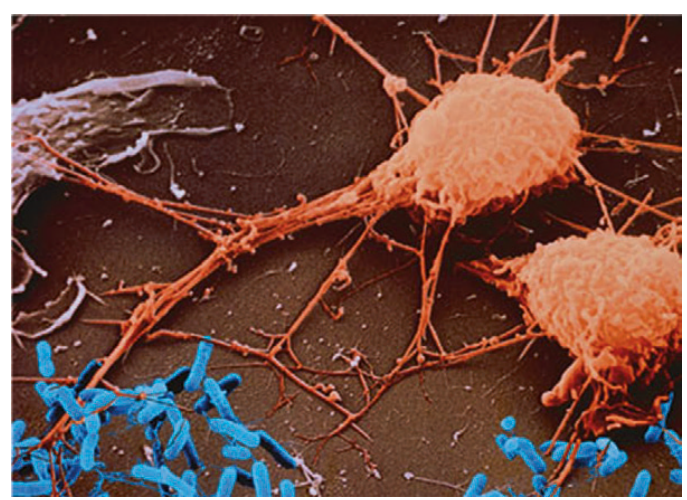

- Abb. 68.1 Kapillargefäß mit Erythrozyten, Leukozyten, Thrombozyten. @ Manfred \& Christina Kage/Okapia 